\title{
TREDJESPRÅKSINLÄRNING OCH METALINGVISTISK MEDVETENHET - ETT DIDAKTISKT PERSPEKTIV
}

\author{
Annika Johansson \\ Stockholms universitet \\ annika.johansson@nederlandska.su.se
}

\begin{abstract}
The contribution deals with third language acquisition and metalinguistic awareness in relation to Swedish and Dutch. The use of posture verbs in the above-mentioned languages is outlined to exemplify the outcome of focusing on metalinguistic awareness in language acquisition as a didactic tool. The contribution will discuss the set up and results of a cloze test taken by Swedish-speaking learners of Dutch, which measures the accurate use of posture verbs.
\end{abstract}

\section{Keywords}

Swedish, Dutch, third language acquisition, posture verbs, metalinguistic awareness, didactics

\section{Inledning}

Svenska och nederländska studeras främst som tredjespråk av vuxna inlärare och tillhör därmed inte de klassiska skolspråken, såsom engelska, tyska, franska eller spanska, som studeras i grundskolan och på gymnasiet. Inlärare av svenska och nederländska har således en annan utgångspunkt och oftast tillgång till flera s.k. bakgrundsspråk vid inlärningsprocessen, framför allt engelska. I denna artikel behandlas först fältet tredjespråksinlärning hos vuxna och därefter hur metalingvistisk medvetenhet kan kopplas till språkinlärning. Metalingvistisk medvetenhet kan didaktiskt användas som en resurs vid språkinlärning och för att exemplifiera detta tas positionsverben i nederländska staan, zitten och liggen respektive i svenska stå, sitta och ligga upp. De svenska och nederländska positionsverbens likheter och skillnader beskrivs varpå ett didaktiskt upplägg diskuteras med utgångspunkt i två lucktest beträffande positionsverb som vuxna inlärare av nederländska vid Stockholms universitet har genomfört.

\section{Tredjespråksinlärning och metalingvistisk medvetenhet}

Svenska och nederländska är typiska tredjespråk (L3) och studeras t.ex. som nybörjarspråk på universitetet. Termen andraspråksinlärning täckte tidigare alla språk som lärdes in efter L1 men under senare år har forskningsfältet tredjespråksinlärning vuxit fram. Begreppen L1, L2 och L3 (samt Ln) skapar en uppfattning om att inlärningen av flera språk följer en viss kronologi. Dock menar Hammarberg $(2016,38)$ att distinktionen främst innebär följande: "Ett tredjespråk (L3) är ett icke-infött språk som lärs eller används i en situation där personen redan har kunskaper i ett eller flera L2 vid sidan av ett eller flera L1". Detta innebär att L3 inte behöver vara inlärarens tredje språk kronologiskt sett utan definitionen hänvisar till att termen L3 används för att beskriva en aktuell inlärningssituation, dvs. det som studeras är en pågående inlärning av ett språk som är icke-infött. Det som då även tas hänsyn till är de s.k. bakgrundsspråken L1 och redan bekanta L2 vilket ger vid handen hur komplex inlärarens språkliga bakgrund är vid

Tijdschrift voor Skandinavistiek 36(2), 2018/19 (co) EY

\footnotetext{
Except where otherwise indicated, the content of this article is licensed and distributed under the terms of the Creative Commons Attribution 3.0 License, which permits unrestricted use, distribution, and reproduction in any medium, provided the original work is properly cited.
} 
inlärningstillfället. Språk lärs sällan in sekventiellt och nivån på språkbehärskningen av tidigare inlärda språk är inte alltid likvärdig och kan utvecklas över tid. I vissa fall är t.ex. kunskapen i ett L2 endast passiv med hör- och läsförståelse och i ett annat L2 modersmålsliknande trots att det språket kanske lärdes in senare. Anledningen till att forskningsfältet L3 har uppkommit hänger ihop med att man vill fokusera på flerspråkigheten hos inlärarna och bl.a. didaktiskt använda sig av inlärarens kompetens och komplexa språkbakgrund som resurs i språkundervisningen.

Inom forskningsfältet tredjespråksinlärning studeras bl.a. det som kallas transfer eller tvärspråklig influens. Odlin $(1989,27)$ definierar transfer enligt följande: "the influence resulting from the similarities and differences between the target language and any other language that has been previously (and perhaps imperfectly) acquired". Vid tredjespråksinlärning har just transfer stor betydelse eftersom inläraren har flera språk att låna språkliga strukturer från än endast L1. Möjligheten att språkliga strukturer transfereras från L2 till L3 är inte försumbar och denna sorts transfer benämner De Angelis \& Selinker "interlanguage transfer " (2001, 43). Vidare gäller att transfer både kan vara positiv respektive negativ. Inlärarna kan använda likheter mellan språken, s.k. positiv transfer, i sin inlärningsprocess och därmed dra fördelar av dessa. När inläraren inte uppfattar skillnader mellan strukturer i språken och lånar in en struktur från ett språk till ett annat trots att strukturen inte överensstämmer mellan språken kan s.k. negativ transfer ske.

I tidig forskning om andraspråksinlärning hänvisades till transfer från L1. Vid introduktionen av forskningsfältet L3 skiftar fokus till att flera bakgrundsspråk kan påverka. Vilket bakgrundspråk som favoriseras som transferkälla styrs av olika samverkande faktorer, enligt Hammarberg $(2016,46)$ :

- graden av aktualitet, dvs. hur mycket språket har använts nyligen

- inlärarens färdighetsnivå i bakgrundsspråket

- graden av typologisk likhet mellan bakgrundsspråket och L3

- L2-status, dvs. inlärarens L2 har en speciell status i inlärningsprocessen och L1 blockeras som transferkälla då det bl.a. har lärts in $\mathrm{i}$ ett icke-formellt sammanhang till skillnad från L2.

Fokus på individuella faktorer hos inläraren har kommit att spela en större roll i forskningen under senare år och faktorn metalingvistisk medvetenhet har diskuterats i detta sammanhang. Det faktum i sig att en individ är två- eller flerspråkig talar för att den har skaffat sig en annan eller större metalingvistisk medvetenhet än enspråkiga individer. Metalingvistisk medvetenhet innebär enligt Jessner (2006, 42):

[...] the ability to focus attention on language as an object in itself or to think abstractly about language and, consequently, to play with or manipulate language. A multilingual certainly makes more use of this ability than a monolingual.

Detta syftar på att tala och resonera om språket själv, dess struktur och funktion. Metalingvistisk medvetenhet kan fylla en viktig funktion vid tredjespråksinlärning hos vuxna. Det faktum att

Tijdschrift voor Skandinavistiek 36(2), 2018/19 (co) EY 
flerspråkiga inlärare ofta redan använder sig av en inlärningsstrategi som bygger på metalingvistisk medvetenhet talar för att ett fördjupande av denna medvetenhet kan användas som ett didaktiskt verktyg i själva lärandemiljön genom att fokusera på och fördjupa kunskapen även om L1 och L2. Beroende på språklig struktur och språkens typologiska närhet kan antingen L1 eller L2 ses som en resurs. Det är därför en poäng att fördjupa metalingvistisk medvetenhet om likheter finns som i fallet med svenska och nederländska. På så vis kan positiv transfer skapas beträffande överensstämmande språkstrukturer och negativ transfer undvikas.

\section{Svenska och nederländska positionsverb}

Positionsverben stå, sitta och ligga respektive staan, zitten och liggen har ett liknande bruk i svenska och nederländska och det finns ett antal studier om verbens semantik för respektive språk (Van Oosten, 1984; Jakobsson, 1996; Lemmens, 2002, 2005; Lemmens \& Slobin, 2008; Viberg, 2010, 2013). Ett antal studier tar även upp didaktiska upplägg beträffande inlärningen av nederländska positionsverb (Lemmens \& Perrez, 2010, 2012; De Knop \& Perrez, 2014) och Viberg diskuterar hur användningen av positionsverben överensstämmer respektive skiljer sig åt för ett antal europeiska språk, däribland nederländska och svenska (2013, 162-163). Positionsverben används frekvent i både svenska och nederländska (Lemmens \& Perrez, 2012; Jakobsson, 1996). Man kan anta att detta hänger ihop med verbens grammatikalisering i det att de inte endast uttrycker mänsklig grundläggande position utan frekvent anger föremåls befintlighet och används i en rad metaforiska uttryck (Lemmens \& Perrez, 2012). Germanska språk som svenska, nederländska och tyska har detta gemensamt medan romanska språk främst använder neutrala verb (jfr. Han sitter i fängelset - Il est en prison "Han är i fängelset") (se De Knop \& Perrez, 2014, 2). Dock saknas i princip systematiska beskrivningar av verben i undervisningsmaterial för språkinlärning vilket för nederländskan har noterats av De Knop \& Perrez (2014, 15-16). I Svensk grammatik på svenska (2009, 147-149) beskrivs verben kortfattat men i övrigt förefaller systematiska beskrivningar även saknas för svenska.

I det följande ges en kortfattad beskrivning av de svenska och nederländska positionsverbens semantik som följer de kategorier som De Knop \& Perrez (2014) har ställt upp för tyska och nederländska. Jämförelsen mellan svenska och nederländska är delvis baserad på sökningar i den bidirektionella korpusen SALT ${ }^{77}$ - svenska-nederländska. Man kan urskilja tre semantiska användningsområden vad gäller positionsverben: människans kroppsliga position när en människa konkret står, ligger och sitter, befintlighet som refererar till den position, s.k. figur (t.ex. föremål), har i förhållande till en konkret plats, s.k. bakgrund (t.ex. låda, skåp, garage) och metaforisk användning där både figur och/eller bakgrund har en abstrakt betydelse. Detta illustreras i (1), (2) och (3).

(1) Kvinnan står i kön (mänsklig position)

De vrouw staat in de rij

(2) Det ligger smulor på bordet (befintlighet)

Er liggen kruimels op de tafel

\footnotetext{
${ }^{77}$ SALT står för Språkbankens Arkiv för Länkade Texter sammanställd av Språkbanken vid Göteborgs universitet.
}

Tijdschrift voor Skandinavistiek 36(2), 2018/19 (cc) Er 
(3) Nu sitter vi verkligen i klistret (metaforisk användning)

$\mathrm{Nu}$ zitten we echt in de puree

Termerna figur och bakgrund ovan används för att beskriva vad som fokuseras i satsen. Dessa termer anger hur något lyfts fram (figur) $\mathrm{i}$ förhållande till något annat som utgör referenspunkten (bakgrund). Figuren kan vara rörlig men inte nödvändigtvis medan bakgrunden gärna är fast (Vogel, 2011, 48) som i (2) Det ligger smulor på bordet. Smulor är här figuren och bordet är bakgrunden.

Användningen av verben stå och ligga i respektive språk uppvisar många likheter beträffande ett föremåls befintlighet. För verben stå-staan handlar det om föremålets bas eller stöd underifrån vilket exemplifieras i Tallriken står på bordet/Het bord staat op tafel. Här nämner Viberg att föremålets funktionella sida aktiveras i användningen av stå $(2013,146)$. Stå-staan kan även användas i den metaforiska domänen gällande skriftligt material såsom i brev, texter och diagram eller på sidor, webbsidor eller tavlor. I (4) och (5) framgår att denna användning aktiveras både i svenska och nederländska, jfr.

(4) Hennes adress står i telefonkatalogen

(5) Haar adres staat in de telefoongids

För ligga-liggen finner man många likheter i bruket av dem i betydelsen befintlighet. Verben kan t.ex. ange en stads eller plats läge, dvs. en sorts geografisk position, illustrerat i (6) och (7).

(6) Stockholm ligger vid Mälaren

(7) De haven van Antwerpen ligt aan de Schelde.

"Antwerpens hamn ligger vid Schelde."

I (6) och (7) kan man se det som att staden respektive hamnen täcker ett geografiskt område. Vid en genomgång av verbet sitta-zitten framträder ett antal likheter och skillnader i användningen i svenska och nederländska. Befintlighet som domän kan t.ex. relateras till att en människa (figuren) befinner sig i en grupp av människor under tvång eller i ett formellt sammanhang, t.ex. fängelse, styrelse, regering (bakgrund), jfr. (8) och (9).

(8) Kvinnan sitter i styrelsen

(9) De vrouw zit in het bestuur

Här kan man anta att det förekommer ett konkret sittande men fokus ligger inte på en mänsklig position utan på deltagande. Skillnader i bruket av sitta-zitten förekommer när figuren omges av ett slutet utrymme. I nederländskan används zitten och i svenskan ligga, som i (10) och (11).

(10) Nycklarna ligger i fickan

(11) De sleutels zitten in de zak

Tijdschrift voor Skandinavistiek 36(2), 2018/19 (co) Eү

Except where otherwise indicated, the content of this article is licensed and distributed under the terms of the Creative Commons Attribution 3.0 License, which permits unrestricted use, distribution, and reproduction in any medium, provided the original work is properly cited. 
Nederländskans zitten motsvaras ofta av svenskans ligga i nämnda kontext vilket framgår av exemplet ovan. Den metaforiska användningen av positionsverben uppvisar störst variation och skillnader i bruk mellan svenska och nederländska. Här följer några exempel på typiska uttryck:

Daar zit ik nog mee, "det grubblar jag fortarande på"

Det sitter i väggarna

Det ligger mig i fatet

Het zit me dwars, "det stör mig"

Dat rokje staat je goed, "den kjolen passar dig bra"

\section{Pilotundersökning}

Kan fokus på metalingvistisk medvetenhet om de nederländska respektive de svenska positionsverbens ovan beskrivna struktur fungera som didaktiskt verktyg vid inlärningen av dem?

\section{Metod}

En pilotundersökning har genomförts med sju deltagare som är vuxna inlärare av nederländska. Deras språkliga nivå motsvarar minst B1 enligt den gemensamma europeiska referensramen för språk (800 timmars språkstudier). Uppgiften gick ut på att deltagarna fyllde i totalt två lucktest innehållande vardera 20 satser där något av verben staan, liggen, zitten, zijn "vara" skulle fyllas i. Det första lucktestet genomfördes utan närmare instruktioner om positionsverb. En månad senare hölls en lektion om positionsverben där positionsverbens tre semantiska användningsområden (se ovan) behandlades ingående och svenska och nederländska kontrasterades med hjälp av ett flertal exempel. Deltagarna hade även i förberedelsesyfte fått i uppgift att läsa en vetenskaplig artikel om positionsverbens funktion i nederländska. Därefter fick deltagarna genomföra ett nytt lucktest med samma verb som ovan.

Deltagarna har angivit svenska som L1 utom två där en har nederländska som L1 och den andra ungerska. Deltagarna har vidare alla angivit engelska som L2 tillsammans med ytterligare språk, t.ex. tyska, spanska och franska. Deltagaren med nederländska som L1 hade genomgående valt korrekt verb vilket kan ses som en bekräftelse på att det finns en överensstämmelse i uppfattning hos modersmålstalare om hur positionsverben används. Antalet deltagare i undersökningen är mycket litet och det går därför inte att dra några definitiva slutsatser av resultatet. Av den anledningen presenteras här inte heller någon statistik. Vissa tendenser kan dock skönjas och några framåtblickar diskuteras.

De fem deltagare som i slutändan tas med i diskussionen har svenska som L1. Dessa deltagare presterade alla bättre på det andra lucktestet. Framför allt är det användningen av zitten i satser där svenska normalt använder ligga som har högre korrekt svarsfrekvens i andra lucktestet, t.ex. Er zit veel snoep in de schaal "det ligger mycket godis i skålen". I första lucktestet har dock deltagarna inte främst använt liggen i dessa satser, vilket skulle ha kunnat vara negativ transfer från svenskan, utan zijn "vara": Er is veel snoep in de schaal. Denna skillnad i bruket av nederländskans zitten i jämförelse med svenska har deltagarna uppmärksammat i andra testet. Ett annat exempel med zitten är satser där subjektet är en deltagare i något slags sammanhang, såsom i Zij zit in het parlement "Hon sitter i parlamentet", se (8) och (9). I första lucktestet har

Tijdschrift voor Skandinavistiek 36(2), 2018/19 (co) EY

\footnotetext{
Except where otherwise indicated, the content of this article is licensed and distributed under the terms of the Creative Commons Attribution 3.0 License, which permits unrestricted use, distribution, and reproduction in any medium, provided the original work is properly cited.
} 
fyra av fem deltagare valt verbet zijn men i andra testet har alla deltagare valt verbet zitten. I några fall överanvänder dock deltagarna zitten i satser där föremålets position föranleder användningen av staan, t.ex. De televisie staat in de woonkamer "Teven står i vardagsrummet". En teveapparat har en funktionell sida och står i rummet (gäller även svenska) men några deltagare har i andra testet valt zitten eftersom de troligen uppfattar att det slutna utrymmet, de woonkamer, i satsen är fokuserat. Denna överanvändning kan troligen härledas till lektionen om positionsverben där nederländskans zitten med fokus på ett slutet utrymme behandlades, jfr. ovan (10) och (11). Samma överanvändning av zitten framträder i andra testet i en presenteringskonstruktion där verbet zijn är det naturliga valet men deltagarna producerade svar som Er zitten veel mensen in de stationshal "Det sitter många människor i stationshallen" och därmed troligtvis tolkar stationshal som att det mänskliga subjektet mensen befinner sig i ett slutet utrymme. Konstruktionen är inte felaktig men anger konkret sittande, inte bara befintlighet.

\section{Konklusion}

Det andra lucktestets förbättrade svarsfrekvens ger en indikation om att en strukturell beskrivning av positionsverben för både svenska och nederländska kan skapa en metalingvistisk medvetenhet hos inläraren om hur dessa verb används och hur användningen skiljer sig åt mellan språken. Dock behövs bättre undervisningsmaterial om positionsverben kopplat till ett utarbetat övningsmaterial. Vad gäller pilotundersökningens upplägg med lucktest skulle ett intressantare resultat kunna nås med "think-aloud protocol" där deltagaren får resonera kring de faktorer som påverkar valet av verb för att på så vis kunna förstå omfattningen av inlärarens metalingvistiska medvetenhet och vilket/vilka språk som eventuellt fungerar som transferkälla.

\section{Bibliografi}

De Angelis, G., Selinker, L. (2001). Interlanguage Transfer and Competing Linguistic Systems in the Multilingual Mind. In: J, Cenoz, B, Hufeisen \& U, Jessner (Eds.). Cross-linguistic Influence in Third Language Acquisition: Psycholinguistic Perspectives (pp. 42-58). Clevedon: Multilingual Matters LTD.

De Knop, S., Perez, J. (2014). Conceptual metaphors as a tool for the efficient teaching of Dutch and German posture verbs. Review of Cognitive Linguistics 12:1, 1-29.

Hammarberg, B. (2016). Flerspråkighet och tredjespråksinlärning. In C, Bardel, Y, Falk \& C, Lindqvist (Eds.), Tredjespråksinlärning (pp.33-58). Lund: Studentlitteratur.

Jakobsson, U. (1996). Familjelika betydelser hos stå, sitta och ligga - en analys ur den kognitiva semantikens perspektiv. Nordlund 21. Lund: Lunds universitet, Institutionen för nordiska språk.

Jessner, U. (2006). Linguistic Awareness in Multilinguals. English as a Third Language. Edingburgh: Edinburgh University Press.

Lemmens, M. (2002). The semantic network of Dutch posture verbs. In J, Newman (ed., Linguistics of Sitting, Standing and Lying, (pp. 103-139). Amsterdam \& Philadelphia: John Benjamins.

Lemmens, M. (2005). Aspectual posture verb constructions in Dutch. Journal of Germanic Linguistics, 17, 183-217.

Tijdschrift voor Skandinavistiek 36(2), 2018/19 (co) EY

Except where otherwise indicated, the content of this article is licensed and distributed under the terms of the Creative Commons Attribution 3.0 License, which permits unrestricted use, distribution, and reproduction in any medium, provided the original work is properly cited. 
Lemmens, M., Slobin, D. (2008). Positie- en bewegingswerkwoorden in het Nederlands, het Engels en het Frans. In Ph, Hiligsman, M, Baelen., A-L, Lelloup \& L, Rasier (Eds.), Verslagen en mededelingen van de Koninklijke Academie voor Nederlandse Taal- en Letterkunde 118, 17-32.

Lemmens, M., Perrez, J. (2010). On the use of posture verbs by French-speaking learners of Dutch: A corpus-based study. Cognitive Linguistics 21(2), pp. 315-347.

Lemmens, M., Perrez, J. (2012). A Quantitative analysis of the use of posture verbs by Frenchspeaking learners of Dutch. CogniTextes, 8. (http://cognitexes.revues.org/533).

Odlin, T. (1989) Language transfer. Cambridge: Cambridge University Press.

Van Oosten, J. (1984). Sitting, standing and lying in Dutch: A cognitive approach to the distribution of the verbs Zitten, Staan and Liggen. In J, Van Oosten \& J, Snapper (Eds.) Dutch Linguistics at Berkeley, (pp. 137-160). Berkeley: Dutch Studies Program, University of California, Berkeley.

Viberg, Å., Ballardini, K. \& Stjärnlöf, S. (2009, 1986). Svensk grammatik på svenska. Stockholm: Natur \& Kultur.

Viberg, ̊. (2010). Swedish Impersonal Constructions from a Cross-linguistic Perspective. An Exploratory Corpus-based Study. Orientalia Suecana vol. 59, 122-158.

Viberg, A. (2013). Posture verbs: A multilingual contrastive study. Languages in Contrast 13:2, 139-169.

Vogel, A. (2011). Språket, kroppen och tankarna. Lund: Studentlitteratur.

\section{Biografisk notis}

Fil. dr. Annika Johansson är sedan 2006 verksam som universitetslektor i nederländska och som studierektor för huvudområdet nederländska vilket inbegriper även studievägledning och erasmuskoordination. Hon är ansvarig för avdelningens pedagogiska verksamhet och har bedrivit kursutveckling för hela grundnivån, senast kandidatkursen i nederländska som startade ht 2015, samt initierat och utvecklat nederländskans distansundervisning. Under perioden 20122014 var hon prefekt för Institutionen för baltiska språk, finska och tyska (inklusive nederländska). Annika Johansson har varit gästlärare vid ett antal tillfällen vid Universiteit Gent och Universiteit van Amsterdam. Sedan 2010 handleder hon avdelningens nederländska lärarpraktikanter i ett samarbete med Universiteit Utrecht. Annika Johansson representerar nederlandistiken i Norden som medlem i styrelsen för Internationale Vereniging voor Neerlandistiek (IVN).

Tijdschrift voor Skandinavistiek 36(2), 2018/19 (cc) Er

Except where otherwise indicated, the content of this article is licensed and distributed under the terms of the Creative Commons Attribution 3.0 License, which permits unrestricted use, distribution, and reproduction in any medium, provided the original work is properly cited. 